Çukurova Üniversitesi Mühendislik Mimarlık Fakültesi Dergisi, 34(1), ss. 103-113, Mart 2019

Çukurova University Journal of the Faculty of Engineering and Architecture, 34(1), pp. 103-113, March 2019

\title{
Sarayönü İlçe Merkezinde Trafik Kaynaklı Gürültü Kirliliğinin Araştırılması
}

\author{
Muhammed Kamil ÖDEN"1, İrem BİLGíN ${ }^{1}$ \\ ${ }^{1}$ Selçuk Üniversitesi, Sarayönü Meslek Yüksek Okulu, Çevre Koruma Teknolojileri Bölümü, Konya
}

Geliş tarihi: 10.07.2018 Kabul tarihi: 27.03.2019

\section{$\ddot{\mathbf{O} z}$}

Bu çalışmada Sarayönü ilçe merkezinin trafik kaynaklı gürültü kirliliği araştırılmıştır. Araştırma kapsamında ilçe merkezinin toplam 44 (kırk dört) adet farklı noktasından gürültü seviyesini belirlemek için ölçümler yapılmıştır. Gürültü ölçümleri Tip-2 gürülttü ölçüm cihazı ile ilgili standartlar dikkate alınarak gerçekleştirilmiştir. Elde edilen gürültü değerleri ise Leq (dBA) olarak hesaplanmıştır. Çeşitli göstergeler dikkate alınarak hesaplanan yüzde ağırlıklı ses seviyeleri $\left(\mathrm{L}_{10}, \mathrm{~L}_{90}, \mathrm{~L}_{\mathrm{eq}}\right)$, arka plan gürültüsü $\left(\mathrm{L}_{90}\right)$ ve tepe değerleri $\left(\mathrm{L}_{10}\right)$ ile vurgulanmıştır. Meteorolojik parametreler olan sıcaklık, rüzgar hızı ve nem değerleri de ölçülerek kayıt altına alınmıştır. İlçe merkezinde trafik gürültünün yaşandığı ana cadde üzerinde eşdeğer gürültü ölçüm seviyelerinin sabah 45-103 dBA, öğlen 44-90 dBA ve akşam 39-82 dBA aralığında olduğu belirlenmiştir. Elde edilen ölçüm noktalarındaki ortalama gürültü düzeyleri Çevresel Gürültünün Değerlendirilmesi ve Yönetimi Yönetmeliği (ÇGDYY) ile kıyaslanmıştır. Tüm periyotların ölçüm ortalamalarına bakıldığında ise 50-70 dBA aralığında olduğu görülmüştür.

Anahtar Kelimeler: Gürültü kirliliği, Sarayönü, Trafik, Ses

\section{Investigation of Traffic Related Noise Pollution in Sarayönü District Center}

\begin{abstract}
In this study, traffic noise pollution of the Sarayönü district center was investigated. Measurements were made in order to determine the environmental noise level from 44 (forty four) different points of the district center. Noise measurements were carried out taking into account the standards related to the Type-2 noise measuring device. The noise values obtained are calculated as Leq (dBA). Percentile weighted sound levels were calculated considering various indicators $\left(\mathrm{L}_{10}, \mathrm{~L}_{90}, \mathrm{~L}_{\mathrm{eq}}\right)$ with special emphasis on background noise $\left(\mathrm{L}_{90}\right)$ and peak values $\left(\mathrm{L}_{10}\right)$. Meteorological parameters such as temperature, wind speed and humidity were also measured and recorded. It was determined that the equivalent noise measurement levels on the main street where traffic noise is experienced in the district center are in the range of 45-103 dBA in the morning, 44-90 dBA in the noon and 39-82 dBA in the evening. The average noise levels at the measurement points obtained are compared with the Environmental Noise Pollution Assessment and Management Regulation (CGDYY). All the periods were found to be in the range of 50$70 \mathrm{dBA}$ when the measurement averages were taken into consideration.
\end{abstract}

Keywords: Noise pollution, Sarayönü, Traffic, Sound

"Sorumlu yazar (Corresponding author): Muhammed Kamil ÖDEN, muhammedkoden@selcuk.edu.tr 


\section{GíRiş}

Ses; gaz, sıvı ve katı gibi farklı ortamlarda ilerleyen mekanik titreşim dalgaları olarak karşımıza çıkmaktadır. Fiziksel boyutta sesi tanımlayacak olursak; katı, siv1 veya gaz ortamlarda oluşan basit bir mekanik düzensizliktir. Herhangi bir maddede bulunan moleküllerin titreşmesi ile oluşur ve kaynaktan aldığ 1 enerjilerle titreşerek yayılmaktadır [1]. Gürültü ise genellikle istenmeyen, hoş olmayan, tahammül edilemeyen bir ses olarak tanımlandığ ve toprak kirliliğinden sonra gelen dördüncü bir kirlilik olarak da adlandırılmaktadır $[2,3]$.

Günümüzde şehir merkezi sorunlardan biri gürültü kirliliği olarak karşımıza çıkmaktadır. Eski çağlarda bile gürültü insanların karşısına çıkan sorun ve/veya bela olarak görülmekteydi. Roma şehrinin ozanları, gürültüyü satirik eserlerinde dile getirmişlerdir. Ünlü bir bilim adamı olan Robert Koch 1910 yılında (Tüberküloz mikrobunu bulan kişi) "Günün birinde insanlar, aynen kolera ve vebada olduğu gibi gürültüyle mücadele etmek zorunda kalacaklardır" demiştir [4]. Bu yüzyıl içerisinde de çok sınırlı sayıda araştırmacı ve bilim adamı arasında konuşulan ve şikayetten öteye gidemeyen çevre kirliliği günümüzde tüm kamuoyunu, sokaktaki vatandaştan, politikacıya ve işadamlarına kadar hemen herkesi ilgilendiren geniş çerçeveli bir küresel boyut kazanmıştır [2]. Hoşa gitmeyen ses olarak tanımladığımız gürültü artık günümüzde insan sağlığı için tehlikeli kirleticilerden biridir. Gürültünün temel kaynaklarına bakıldığında endüstri, ulaşım, yol ve yapım çalışmaları ile yerleşim kaynaklı türlerden oluşmaktadır. Kişisel ve toplumsal değişiklikler görülmekte birlikte eşdeğer gürültü seviyesi 55 dBA'yı aştığında rahatsızlıkların başladığı ve 65 dBA ve üzerinde olduğunda, uykunun önemli biçimde bölündüğü ve insanların büyük bir çoğunluğunun gürültüden rahatsız olduğu kabul edilmektedir [5].

Gürültü kirliliği insan, hayvan, bitki ve doğal çevreyi olumsuz yönde etkileyebildiği yapılan araştırmalarda çok daha iyi anlaşılmaya başlanmıştır. Gürültünün sağlık üzerine etkilerini inceleyen çalışmalar yapılmış ve yapılmaya devam edilmektedir. Yerli, yabancı birçok çalışmada, gürültünün olumsuz etkilerinin azımsanmayacak derecede önemli ve çok olduğu belirtilmektedir [6].

Gürültünün etkisine karşı insan davranışları iki grupta toplanmaktadır. Birincisi, ancak duygu ve duyuların açıklanmasıyla belirlenebilen psikolojik rahatsızlık, ikincisi ise; çeşitli ölçme metotlarıyla belirlenebilen fizyolojik rahatsızlıktır. Bu sebeple, insan sağlığı ve konfor şartları açısından mimari tasarım aşamasında gürültü kontrolü yapılması gerekir [7]. Elbette bunların dışında sesin, elastikiyeti, hacmi, şiddeti, maruziyet şekli, gürültünün süresi ve tipi gibi dikkate alınması gereken birçok etken olduğu unutulmamalıdır. Çizelge 1'de gürültünün etkilerine yönelik bir sinıflandırma yer almaktadır.

Çizelge 1. Gürültünün etki sınıflandırması [7]

\begin{tabular}{|c|c|}
\hline Derecesi & Etkisi \\
\hline $\begin{array}{c}\text { I. Derece } \\
\text { Gürültüler } \\
(30-65 \mathrm{dBA})\end{array}$ & $\begin{array}{c}\text { Konforsuzluk } \\
\text { Rahatsızlık } \\
\text { Sıkılma duygusu } \\
\text { Kızgınlık } \\
\text { Konsantrasyon } \\
\text { Uyku Bozukluğu }\end{array}$ \\
\hline $\begin{array}{c}\text { II. Derece } \\
\text { Gürültüler } \\
(65-90 \mathrm{dBA})\end{array}$ & $\begin{array}{c}\text { Fizyolojik gürültü } \\
\text { Kalp atışının değişimi } \\
\text { Solunum hızlanması } \\
\text { Beyindeki basıncın azalması }\end{array}$ \\
\hline $\begin{array}{c}\text { III. Derece } \\
\text { Gürültüler } \\
(90-120 \mathrm{dBA})\end{array}$ & $\begin{array}{c}\text { Fizyolojik gürültü } \\
\text { Baş ağrısı }\end{array}$ \\
\hline $\begin{array}{c}\text { IV. Derece } \\
\text { Gürültüler } \\
(120-140 \mathrm{dBA})\end{array}$ & İç kulakta bozukluk \\
\hline $\begin{array}{c}\text { V. Derece } \\
\text { Gürültüler } \\
(>140 \mathrm{dBA})\end{array}$ & Kulak zarının patlaması \\
\hline
\end{tabular}

İnsanlar, kabul edilebilir gürültüyü algılamada farkl11ıklar gösterebilmektedir. Bu bakımdan ses kavramı nesnel iken gürültü ise öznel olarak tanımlanmaktadır. Hangi seslerin gürültü olduğunu ise kişilerin toleransları belirlemektedir [1]. Avrupa ülkelerini kapsayan bir çalışmada, söz konusu ülkelerde yaşayan toplam 371.602.000 
kişiden \%32'sinin $55 \mathrm{dBA}$, \%13'ünün ise $65 \mathrm{dBA}$ üzerindeki gürültülerden etkilendiği belirlenmiştir $[8,9]$. Araştırma Konya İli, Sarayönü İlçe merkezinin en yoğun faaliyet alanı içinde yürütülmüştür. $\mathrm{Bu}$ araştırmada ulaşım, inşaat, yerleşim ve ticaret gibi ilçenin önemli merkezlerinden olan Ankara ve Tahir Çelik caddelerinde 08:00-23:00 saatleri arasında Mart, Nisan ve Mayıs ayları içerisinde ölçümler gerçekleştirilmiştir. Ölçüm yeri olan Konya ili, coğrafi konum olarak $36^{\circ} 41^{1}$ ve $39^{\circ} 16^{1}$ kuzey enlemleri ile $31^{\circ} 14^{1}$ ve $34^{\circ} 26^{1}$ doğu boylamları arasında yer almakta olup ortalama yüksekliği 1.016 m'dir. [10,11]. Sarayönü İlçe merkezi Konya-Afyon devlet kara yolunun $44 \mathrm{~km}$ 'sinde 7 km'lik asfalt il yolu ile bağlı olup; Konya'ya $51 \mathrm{~km}$ uzaklıktadır. İlçenin genel nüfusu 26.450'tir. Nüfusun yaklaşık \%52'si kadın, \%48'i erkek nüfustur [12]. İlçeye ait harita görüntüsü Şekil 1'de yer almaktadır.

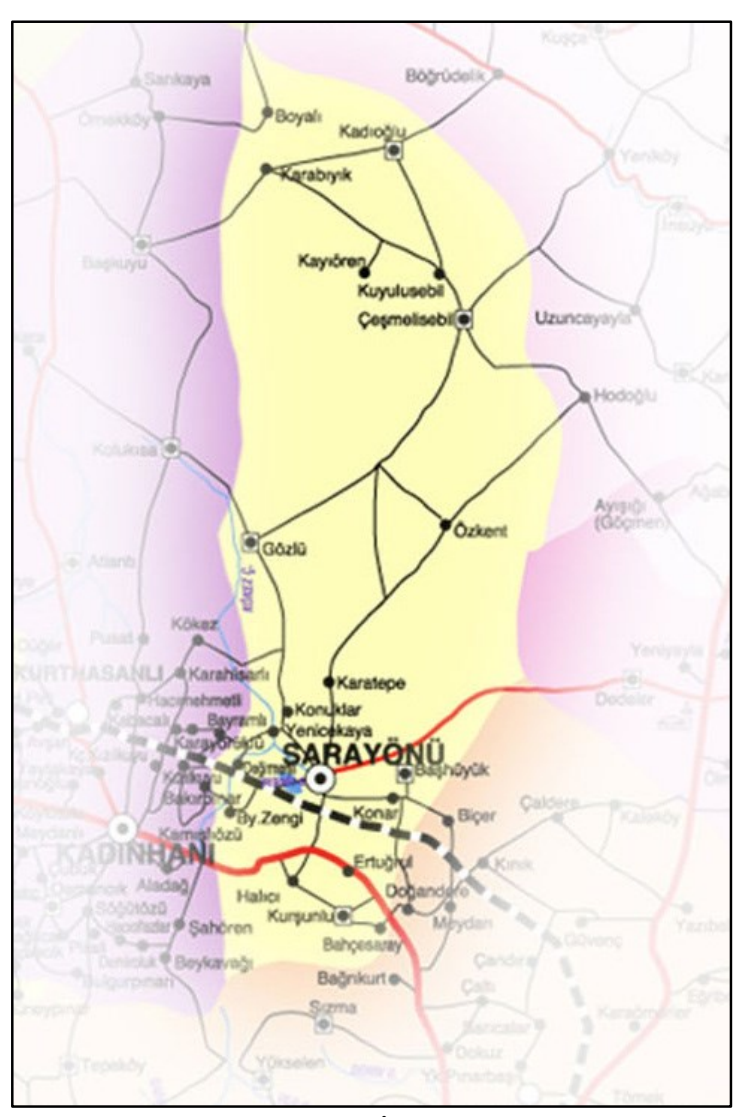

Şekil 1. Sarayönü İlçe haritası [12]
Araștırmanın amacı, ilçede en önemli sorun olan trafik ve motorlu araçlardan kaynaklanan yoğunluğa dikkat çekmek ve yapılacak ölçümlerle trafikten kaynaklı gürültü kirlilik düzeyinin saptanmas1, gürültü kirliliği grafiklerinin oluşturulması ve alternatif çözüm önerilerinin geliştirilmesidir. Ulaşımdan kaynaklanan gürültü, çevresel gürültü kirliliğinin birincil kaynaklarındandır ve pek çok açıdan karmaşık bir meseledir. Genel bir kural olarak, daha büyük ve daha ağır araçlar daha fazla gürültü üretir. Yoldaki araçların gürültüsü temel olarak motordan ve araçla yerin ve havanın sürtünmesinden kaynaklanır. Genelde yolla temastan kaynaklanan gürültü, $60 \mathrm{~km} / \mathrm{h}$ 'den daha yüksek hızlarda motordan kaynaklanan gürültünün üstüne çıkabilmektedir [13]

\section{MATERYAL VE METOT}

Bu çalışma kapsamında Konya İli, Sarayönü İlçe merkezinde motorlu taşıtlardan kaynaklı gürültü kirliliğinin düzeylerinin tespiti ile durum analizlerini gerçekleştirmek amacıyla 44 farklı noktada ölçümler yapılmıştır. Gürültü ölçüm noktaları ulaşım, inşaat, yerleşim ve ticaret gibi ilçenin önemli faaliyet merkezlerinden olan Ankara ve Tahir Çelik caddelerinin olması uygun görülmüştür. Caddeler üzerinden 08:00-23:00 saatleri arasında Mart-Nisan ve Mayıs aylarında ölçüm ve değerlendirmeler yapılmıştır. Yapılan gürültü ölçümleri TS 3744, TS ISO 1996-1 (TS 9315) ve 1996-2 standartları dikkate alınarak gerçekleştirilmiştir [9,14]. Elde edilen ölçüm noktalarına ait $\mathrm{L}_{\text {Aeq }}$ değerleri (Leq, Eşdeğer gürültü seviyesi) aşağıdaki denklem ile hesaplanmaktadır (Eşitlik 1).

LAeq $=10 \log \frac{1}{10} \sum_{\mathrm{i}=1}^{\mathrm{n}} 10^{\mathrm{Li} / 10}$

Trafik gürültü indeksi;

$\mathrm{TGI}=4\left(\mathrm{~L}_{10}-\mathrm{L}_{90}\right)+\left(\mathrm{L}_{90}-30\right)$

Eşitlik (2) ile tarif edilmektedir. Esas ölçü birimi dışında 24 saatlik zaman periyodunda ölçülen 
ağırlıklı bir gürültü seviyesidir. Trafik dışındaki arka plan gürültüsünden kaynaklanan belirsizlik nedeniyle TGI'nın tespiti ve ölçümü zordur $[15,16]$. $L_{10}$ : ölçülen gürültülerin $\% 10$ 'unun eşit veya daha büyük olduğu gürültü seviyesi, $L_{90}$ : ölçülen gürültülerin \%90'ının eşit olduğu gürültü seviyesidir $[17,18]$.

Birçok ses seviyesi ölçer genellikle hızlı ve yavaş konumda çalışabilir. Hızlı konum, saniyenin 8'de 1 'inde ortama gürültü seviyesini oldukça doğru bir şekilde verir. Böylece bir akustik sinyalin zamana bağlı kalitesi kolayca analiz edilebilir. Ama en doğrusu yavaş konumda ölçüm yapmaktır. Yavaş konum daha detaylı ve 1 saniye'lik zaman için ölçüm yapmaktadır. Desibel ölçüm ve kayıt cihazı olarak CEM dt-8852 cihazından yararlanılmıs kontrol için ise LYK bgm 1356 cihazı kullanılmıştır. LYK bgm8908 marka dijital rüzgâr ölçer (anemometre) ve sıcaklık ölçer kullanılmıştır. Cihaz Tip-2 sınıfina girmekte olup, tedarikçi firmadan kalibrasyonlu olarak teslim alınmıştır. Cihazın en yüksek pik ses basınç seviyesi 130 dBA olup, 30-130 dBA aralığındaki gürültü seviyelerini ölçebilmektedir. Ses seviye ölçerin \pm 1,5 $\mathrm{dB}$ hassasiyet payı ile son derece hassas bir ses desibel ölçüm performansını sağlamaktadır.
Ölçüm planlaması sırasında belirlenen ve koordinatları alınan 44 adet ölçüm istasyonunda (ölçüm noktasında) 2018 yılı ilkbahar döneminde trafiğin yoğun olduğu 08.00-23.00 saatleri arasında gürültü ölçümleri yapılmıştır. Ölçümler gürültü seviyesi ölçülecek karayolunun kenarında bulunan kaldırımların yola bakan kenarlarında yerden yaklaşık 1,5 metre yükseklikte gerçekleştirilmiştir. Ölçüm yüksekliği seçiminde yerden 1,5 metre $[9,19,20], 1,2$ metre [14,21,22], 1,2-1,5 metre [7] ve 1,65-1,80 metre [23] yükseklikte araştırmalar yapılmıştır.

\section{BULGULAR VE TARTIŞMA}

Ölçümler sırasında rüzgar hızı, sıcaklık ve nem verileri de kayıt altına alınmıştır. İlçenin merkez caddesi olan Ankara ve Tahir çelik üzerinde olan sıhhi ve gayrisıhhi müesseselere ait bilgiler Şekil 2'de verilmiştir. Caddeye ait teknik bilgiler ise Çizelge 2'de verilmiştir. Bu çalışma sırasında ölçüm yapılacak konumun ve yönteminin belirlenmesi, literatürde yer alan yardımcı kaynakların incelenmesi, ölçüm sonuçlarının kıyaslanması, ses seviye ölçümleri, ölçüm datalarına göre çıkarım ve sonuçlar gerçekleştirilmiştir.

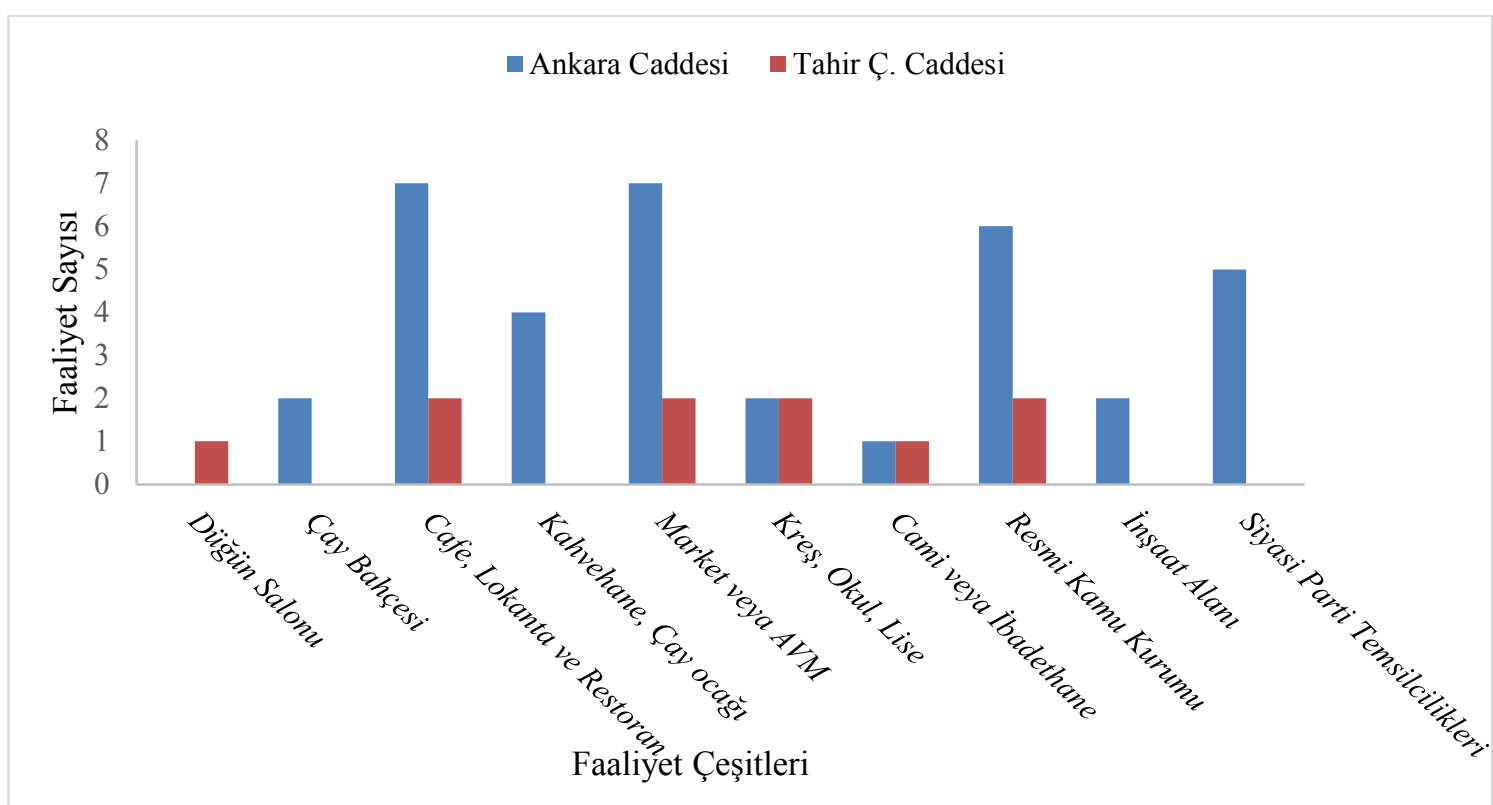

Şekil 2. İlçe merkezindeki bazı faaliyet kolları dağılımı 
Çizelge 2. Caddelere ait teknik bilgiler

\begin{tabular}{|l|c|c|c|c|c|c|c|c|}
\hline Cadde Adı & $\begin{array}{c}\text { Cadde } \\
\text { Üzerinde } \\
\text { Ev Sayısı }\end{array}$ & $\begin{array}{c}\text { Cadde } \\
\begin{array}{c}\text { Uzzerinde } \\
\text { İsyeri Sayısı }\end{array}\end{array}$ & $\begin{array}{c}\text { Tek Yol } \\
\text { Genişlik } \\
\text { (m) }\end{array}$ & $\begin{array}{c}\text { Şerit } \\
\text { Sayısı }\end{array}$ & $\begin{array}{c}\text { Trafik Akış } \\
\text { Ortalaması } \\
\text { (taşıt/saat) }\end{array}$ & $\begin{array}{c}\text { Uzunluk } \\
\text { (m) }\end{array}$ & $\begin{array}{c}\text { Uzunluk } \\
\text { (m) }\end{array}$ & $\begin{array}{c}\text { Kavşak } \\
\text { Sayısı }\end{array}$ \\
\hline Ankara & $76^{*}$ & $112^{* *}$ & 7 & 2 & 20 & 510 & 510 & 3 \\
\hline Tahir Çelik & $32^{*}$ & $20^{* *}$ & 7 & 2 & 27 & 440 & 440 & 3 \\
\hline
\end{tabular}

* Toplam 6 boş ev

** Toplam 19 boş işyeri

Gürültü kirliliği seviyesi olarak, eşdeğer gürültü seviyesini ifade eden $L_{e q}$ değeri kullanılmıştır. Çalışma sırasında ölçüm dataları toplanırken, her ölçüm noktasında 4'er adet eşdeğer gürültü ölçümü yapılmıştır. Eşdeğer gürültü ölçümü seviyelerinin $\left(\mathrm{L}_{\text {eq }}\right)$ ortalamaları hesaplanmış ve ilgili ölçüm istasyonlarının gürültü seviyeleri tespit edilmiştir.

Trafikten kaynaklı gürültü ölçüm düzeylerinin sabah 08:00-12:00, öğlen 12:00-17:00 ve akşam 17:00-23:00 saatlerinde ölçülerek kayıt edilmiştir. 44 ölçüm noktasında 4'er adet ölçüm gerçekleştirilmiş olup aynı zamanda kayıt altına alınan meteorolojik veriler yer almaktadır. Ölçümler sırasında çevresel parametrelerden sıcaklık, nem, rüzgâr, yağış, bulutluluk, bina ve yerin etkisi gibi kısımlara dikkat edilmiştir. Ölçüm sırasında kayıt edilen gürültü düzeylerinden minimum, maksimum ve ortalama değer ile ölçüm çevre şartlarından rüzgâr hızı, sıcaklık ve nem verileri kayıt altına alınarak aşağıdaki Çizelge 3-5'de verilmiştir.

Çizelge 2 içerisinde Ankara ve Tahir Çelik caddelerine ait bazı istatistik veriler bulunmaktadır. Merkez cadde konumunda olan alan üzerinde oldukça fazla insan ve taşıt faaliyeti bulunmaktadir. Faaliyet neticesinde ise hem trafik hem de çevresel bir gürültü oluşmakta ve gürültü kirliliğine katkı sağladığı görülmektedir. Toplam cadde uzunluğu 950 metre olup ortalama trafik yoğunluğu ise yaklaşık 700 taşıt/gün gibi gözükmektedir. Bölgenin başlıca gelir kaynağ tarım ve hayvancılık olması zirai alet ve ekipmanların trafikteki varlığının nedenleri arasında yer almaktadır.

$\mathrm{L}_{10}, \mathrm{~L}_{50}, \quad \mathrm{~L}_{90}$ en çok kullanılan istatistiki değerlerdir. $\mathrm{L}_{10}$, yüksek düzey ve kısa süreli gürültülerin ortalama bir ölçümünü verir. $\mathrm{L}_{50}$, orta ses seviyesidir ve zamanın \%50 sinde aşılan ses seviyesini gösterir. L90 ise zamanın \%90'ında aşılan ses seviyesini gösterir [7]. Trafik Gürültü indeksi TGI veya TNI ile ifade edilebilmektedir. Londra'da sosyal bir araştırma sonuçlarına istinaden oluşturulmuştur. Ancak L 90 değerinin güvenilir bir şekilde tahmini zor olmasından dolayı TGI'da hatalar olmuştur. Örneğin trafiğin arttığında TGI azalabilmektedir. $\mathrm{Bu}$ gibi durumlardan dolayı İngiltere' de bu ölçüm yöntemi, yapılan araştırmalara sağladığı katkı sonucuna rağmen bırakılmıştır [18]. İstatistiki ses seviyeleri ilişkin gündüz, öğlen ve akşam için ayrı ayrı hesaplanmıştır. Sırasıyla $\mathrm{L}_{10}$ : 89,02, 86,48, 81,34, L90: 78,27, 77,73, 73,25 ve TGI: $91,26,82,73$ ve 75,61 olarak hesaplanmıştır.

Çizelge 3-5'de veriler yerleştirilirken gürültü noktalarındaki ses seviyeleri, rüzgâr hızı, sıcaklık ve nem miktarları arasında bir kıyaslama yapılmasına müsaade edecek şekilde verilmiştir. İlgili çizelgeler içerisinde aynı zamanda gürültü seviyelerine ilişkin standart sapma dataları da sunulmuştur.

Çizelge 3'de verilen gündüz ölçümlerinde rüzgâr hizı 0,8-2,05 m/s, sicaklık 24,5-30,5 ${ }^{\circ} \mathrm{C}$, nem ise \%21,5-33 değerleri arasında ölçülmüştür. Bununla birlikte elde edilen gürültüye ait ses seviyesi ise 45,5 ile 102,5 dBA aralı̆̆ında seyretmiştir. Meteorojik verilerden rüzgar hızı ve nem değişimine ait zaman dilimlerinde ses seviyesinde azalma veya artma olduğu gözlemlenmiştir. Çizelge 4 içerisinde yapılan öğlen zaman dilimine ait veriler bulunmaktadır. Bu verilere ait en düşük ve en yüksek meteorolojik datalar ise rüzgâr hızı için $0,8-2,35 \mathrm{~m} / \mathrm{s}$, sicaklık için $21,9-27,6{ }^{\circ} \mathrm{C}$, nem için ise \%33-37'dir. 12:00-17:00 saatlerine ait zaman diliminde gerçekleşen ölçümlerde elde edilen gürültü düzeyleri 44,3 ile 89,8 dBA 
aralığında olduğu kayıt altına alınmıștır. Çizelge 5'de akşam ölçümlerine ait veriler yer almakta olup rüzgâr hızı aralığ $0,8-2,65 \mathrm{~m} / \mathrm{s}$, sıcaklık aralığ $20-22,5{ }^{\circ} \mathrm{C}$, nem oranı ise \%35-39 değerleri ölçüm sırasında kayıt edilmiştir. Ses seviyelerine ilişkin verilerde 39,0 ile 82,2 dBA aralığında ölçülmüştür.

Çizelge 3-5 incelendiğinde ortalama trafik gürültü seviyeleri sabah 63,6 dBA, öğlen 64,2 dBA ve akşam için ise 58,8 dBA olduğu görülmektedir. Çalışma alanına ait gürültünün kaynaklandıktan sonra bir engel veya yansıtıcı yüzey varlığına karşı göstereceği tahmini örnek gösterim hazırlanmıştır. Sarayönü ilçesinin Google Earth görüntüsünden faydalanılarak bilgisayar destekli tasarım programından faydalanılarak renklendirilmiştir. Tahmini örnek gösterime ait uydu görüntüsü Şekil 4'de yer almaktadır.

Çizelge 3. Tahir Çelik-Ankara caddeleri sabah (08:00-12:00) gürültü ölçümü verileri

\begin{tabular}{|c|c|c|c|c|c|c|c|c|c|c|c|c|c|c|c|c|c|c|c|c|c|c|c|}
\hline \multicolumn{2}{|c|}{ Ölçüm Noktaları } & 1 & 2 & 3 & 4 & 5 & 6 & 7 & 8 & 9 & 10 & 11 & 12 & 13 & 14 & 15 & 16 & 17 & 18 & 19 & 20 & 21 & 22 \\
\hline \multirow{4}{*}{$\begin{array}{l}\text { Ses } \\
\text { seviyesi, } \\
\text { dBA }\end{array}$} & En az & 52,2 & 53,1 & 51,4 & 52,4 & 39,6 & 51,2 & 50,2 & 48,9 & 49,9 & 51,2 & 52,3 & 49,2 & 47,2 & 48,6 & 53,2 & 53,4 & 47,5 & 57,1 & 57,0 & 52,4 & \begin{tabular}{|l|}
50,7 \\
\end{tabular} & 50,6 \\
\hline & En çok & 85,4 & 102,5 & 77 & 73,6 & 80,4 & 73,7 & 69,7 & 74,8 & 78,3 & 72,7 & 72,7 & 74,3 & 73,9 & 72,9 & 67,8 & 75,7 & 71,2 & 74,1 & 80,0 & 74,4 & \begin{tabular}{|l|}
78,2 \\
\end{tabular} & 83,6 \\
\hline & Ort & 7,6 & 69,75 & 63,4 & 63,3 & 62,4 & 62,4 & 61,2 & 61,6 & 63,0 & 62,9 & 60,5 & 61,6 & 62,1 & 60,7 & 60,3 & 63,9 & 59,6 & 62,9 & 67,1 & \begin{tabular}{|l|}
60,0 \\
\end{tabular} & 3,7 & 66,2 \\
\hline & SD & 2,6 & 19,7 & 10,1 & 9,7 & 16,0 & 9,6 & 8,1 & 10,6 & 13,1 & 8,7 & 8,5 & 9,2 & 11,3 & 11,0 & 6,2 & 9,7 & 10,4 & 7,9 & 9,2 & 8,8 & 10,5 & 12,1 \\
\hline \multicolumn{2}{|c|}{$\begin{array}{l}\text { Ortalama rüzgâr } \\
\text { hızı, m/s }\end{array}$} & 1,1 & 1,15 & 1,05 & 1,0 & 1,2 & 1,7 & 1,1 & 1,2 & 1,3 & 1,4 & 1,4 & 0,9 & 1,0 & 2,0 & 1,5 & 0,95 & 1,5 & 1,0 & 1,3 & 1,4 & 1,1 & 1,5 \\
\hline \multicolumn{2}{|c|}{$\begin{array}{l}\text { Ortalama } \\
\text { sicaklık, }{ }^{\circ} \mathrm{C}\end{array}$} & 25,8 & 25,85 & 26,35 & 27,1 & 27,2 & 27,8 & 27,8 & 27,8 & 28,2 & 28,0 & 28,1 & 27,9 & 27,9 & 27,6 & 28,0 & 28,0 & 28,0 & 28,5 & 29,2 & 29,5 & 30,3 & 29,9 \\
\hline \multicolumn{2}{|c|}{ Ortalama nem, $\%$} & 31,5 & 33 & 33 & 31 & 31,5 & 28,5 & 27,5 & 27,5 & 27,5 & 28 & 2,5 & 27,5 & 27,5 & 28,5 & 27,5 & 26,0 & 26,0 & 27,5 & 27,5 & 25,5 & 25,0 & 23,5 \\
\hline \multicolumn{2}{|c|}{ Ölçüm Noktaları } & 23 & 24 & 25 & 26 & 27 & 28 & 29 & 30 & 31 & 32 & 33 & 34 & 35 & 36 & 37 & 38 & 39 & 40 & 41 & 42 & 43 & 44 \\
\hline \multirow{4}{*}{$\begin{array}{l}\text { Ses } \\
\text { seviyesi, } \\
\text { dBA }\end{array}$} & En az & 53,2 & 50,1 & 53,1 & 47,9 & 51,4 & 50,6 & 50,0 & 54,6 & 55,5 & 62,2 & 47,8 & 52,1 & 52,3 & 57,9 & 55,6 & 45,5 & 46,5 & 49,6 & 48,5 & 47,9 & 45,7 & 48,4 \\
\hline & En çok & 74,9 & 87,6 & 77,6 & 71,2 & 82,5 & 75,4 & 72,7 & 75,5 & 75,5 & 80,1 & 84,5 & 71,4 & 74,4 & 74,4 & 85,1 & 82,3 & 81,1 & 80,0 & 77,3 & 79,8 & 81,6 & 79,0 \\
\hline & Ort & 63,1 & 66,2 & 63,9 & 60,6 & 64,5 & 62,8 & 61,0 & 64,7 & 63,3 & 70,2 & 64,2 & 61,3 & 62,4 & 66,5 & 68,5 & 63,6 & 62,3 & 62,7 & 65,8 & 64,3 & 61,9 & 66,1 \\
\hline & SD & 8,5 & 14,2 & 8,9 & 10,4 & 12,6 & 12,0 & 10,6 & 9,4 & 8,3 & 6,7 & 13,9 & 8,3 & 9,6 & 7,1 & 12,9 & 15,1 & 13,8 & 12,1 & 12,1 & 13,1 & 14,0 & 13,1 \\
\hline \multicolumn{2}{|c|}{$\begin{array}{l}\text { Ortalama rüzgâr } \\
\mathrm{hızl}, \mathrm{m} / \mathrm{s}\end{array}$} & 1,3 & 1,5 & 0,8 & 0,8 & 0,9 & 1,5 & 1,5 & 1,5 & 2,1 & 1,5 & 1,6 & 2,0 & 1,7 & 0,9 & 0,9 & 1,7 & 1,3 & 2,0 & 1,7 & 1,1 & 1,3 & 1,3 \\
\hline \multicolumn{2}{|c|}{$\begin{array}{l}\text { Ortalama } \\
\text { Sicaklık, }{ }^{\circ} \mathrm{C}\end{array}$} & 29,8 & 29,9 & 29,2 & 27,8 & 27,1 & 26,0 & 25,4 & 25,1 & 24,7 & 24,6 & 24,5 & 24,6 & 24,8 & 25,1 & 25,2 & 27,2 & 26,8 & 26,4 & 26,5 & 26,2 & 25,9 & 26,0 \\
\hline \multicolumn{2}{|c|}{ Ortalama nem \% } & 22,0 & 22,0 & 22,0 & 21,5 & 22,5 & 24,0 & 24,5 & 24,5 & 26,0 & 28,0 & 25,5 & 25,5 & 26,5 & 26,5 & 27,0 & 24,5 & 25,0 & 24,5 & 24,5 & 24,0 & 23,5 & 24,0 \\
\hline
\end{tabular}

En az: Minumum, En çok: Maksimum, Ort: Ortalama ve SD: Standart Sapma

Çizelge 4. Tahir Çelik-Ankara caddeleri öğlen (12:00-17:00) gürültü ölçümü verileri

\begin{tabular}{|c|c|c|c|c|c|c|c|c|c|c|c|c|c|c|c|c|c|c|c|c|c|c|c|}
\hline \multicolumn{2}{|c|}{$\begin{array}{l}\text { Ölçüm } \\
\text { Noktaları }\end{array}$} & 1 & 2 & 3 & 4 & 5 & 6 & 7 & 8 & 9 & 10 & 11 & 12 & 13 & 14 & 15 & 16 & 17 & 18 & 19 & 20 & 21 & 22 \\
\hline \multirow{4}{*}{$\begin{array}{l}\text { Ses } \\
\text { seviyesi, } \\
\text { dBA }\end{array}$} & En az & 56,7 & 52,8 & 49,3 & 44,3 & 54,4 & 52,4 & 51,2 & 49,5 & 49,9 & 50,4 & 54,0 & 53,0 & 51,6 & 53,0 & 53,2 & 57,2 & 55,6 & 47,4 & 57,3 & 54,1 & 53,4 & 52,0 \\
\hline & En çok & 75,2 & 74,8 & 83,7 & 77,8 & 82,1 & 81,3 & 86,5 & 74,0 & 77,7 & 72,9 & 89,8 & 78,9 & 75,5 & 67,0 & 71,3 & 70,9 & 74,6 & 73,7 & 73,7 & 81,4 & 74,0 & 77,2 \\
\hline & Ort & 66,4 & 61,7 & 67,9 & 61,3 & 67,0 & 66,3 & 66,0 & 61,7 & 62,9 & 63,0 & 67,7 & 69,0 & 63,9 & 60,0 & 62,3 & 66,2 & 66,7 & \begin{tabular}{|l|}
61,2 \\
\end{tabular} & 65,1 & 67,2 & 65,1 & 64,1 \\
\hline & SD & 8,1 & 8,5 & 15,3 & 13,0 & 12,6 & 10,3 & 13,8 & 11,5 & 11,2 & 9,6 & 14,3 & 10,4 & 9,3 & 6,1 & 8,5 & 7,9 & 7,7 & 11,9 & 7,2 & 9,9 & 7,8 & 11,4 \\
\hline \multicolumn{2}{|c|}{$\begin{array}{l}\text { Ortalama } \\
\text { rüzgâr hızı, m/s }\end{array}$} & 1,4 & 1,4 & 1,5 & 2,0 & 1,3 & 2,3 & 1,7 & 1,4 & 2,0 & 0,9 & 1,2 & 1,0 & 0,8 & 1,3 & 1,5 & 1,7 & 1,2 & 0,8 & 1,3 & 1,7 & 1,4 & 1,9 \\
\hline \multicolumn{2}{|c|}{$\begin{array}{l}\text { Ortalama } \\
\text { sicaklık, }{ }^{\circ} \mathrm{C}\end{array}$} & 1,9 & 22,7 & 22,9 & 23,6 & 23,9 & 24,0 & 24,2 & 24,5 & 24,1 & 23,7 & 23,6 & 23,5 & 23,3 & 23,1 & 22,8 & 22,8 & 23,0 & 23,2 & 23,2 & 22,9 & 23,9 & 22,8 \\
\hline \multicolumn{2}{|c|}{$\begin{array}{l}\text { Ortalama } \\
\text { nem, } \%\end{array}$} & 5,0 & 34,5 & 35,0 & 36,5 & 35,0 & 35,0 & 35,0 & 33,0 & 34,5 & 34,5 & 34,0 & 33,0 & 35,5 & 35,5 & 35,0 & 35,0 & 36,0 & 36,0 & 36,0 & 36,0 & 35,5 & 36,0 \\
\hline \multicolumn{2}{|c|}{$\begin{array}{l}\text { Ölccüm } \\
\text { Noktaları }\end{array}$} & 23 & 24 & 25 & 26 & 27 & 28 & 29 & 30 & 31 & 32 & 33 & 34 & 35 & 36 & 37 & 38 & 39 & 40 & 41 & 42 & 43 & 44 \\
\hline \multirow{4}{*}{$\begin{array}{l}\text { Ses } \\
\text { Seviyesi, } \\
\text { dBA }\end{array}$} & En az & & 51,6 & 47,2 & 52,8 & 53,8 & 51,8 & 47,3 & 49,9 & 53,0 & 51,4 & 52,2 & 50,7 & 48,5 & 55,5 & 52,6 & 48,4 & 55,0 & 47,1 & 49,3 & 53,0 & 3,8 & 51,0 \\
\hline & En çok & 7,8 & 76,9 & 71,0 & 78,9 & 80,3 & 75,6 & 69,6 & 73,3 & 79,9 & 77,3 & 83,3 & 75,5 & 57,8 & 89,1 & 71,2 & 75,6 & 79,5 & 74,8 & 80,4 & 81,2 & & 3,5 \\
\hline & Ort & 67,8 & 65,2 & 59,0 & 66,8 & 67,9 & 63,2 & 58,5 & 62,9 & 65,3 & 63,3 & 64,0 & 64,2 & 60,0 & 68,0 & 62,5 & 62,0 & 66,3 & 61,4 & 63,5 & 66,1 & 63,9 & 61,5 \\
\hline & SD & 7,7 & 10,7 & 11,4 & \begin{tabular}{|l|}
11,9 \\
\end{tabular} & 9,4 & 11,0 & 9,5 & 10,1 & 10,8 & 12,0 & 11,8 & 11,2 & \begin{tabular}{|l|}
7,8 \\
\end{tabular} & 13,7 & 8,5 & 11,5 & 10,0 & 12,3 & 14,0 & 11,8 & 12,0 & 9,3 \\
\hline \multicolumn{2}{|c|}{$\begin{array}{l}\text { Ortalama } \\
\text { rüzgâr hızı, m/s }\end{array}$} & 1,2 & 1,0 & 1,0 & 1,1 & 1,8 & 1,6 & 1,6 & 1,0 & 0,9 & 1,5 & 2,0 & 0,9 & 1,5 & 1,5 & 1,3 & 1,6 & 1,5 & 0,9 & 1,1 & 1,5 & 1,2 & 1,0 \\
\hline \multicolumn{2}{|c|}{$\begin{array}{l}\text { Ortalama } \\
\text { sicaklık, }{ }^{\circ} \mathrm{C}\end{array}$} & 23,5 & 23,7 & 24,1 & 24,7 & 25,1 & 25,5 & 25,8 & 26,0 & 26,7 & 27,1 & 27,5 & 27,7 & 27,6 & 27,2 & 27,0 & 27,1 & 26,9 & 26,8 & 26,8 & 26,8 & 26,8 & 26,8 \\
\hline \multicolumn{2}{|c|}{$\begin{array}{l}\text { Ortalama } \\
\text { nem, } \%\end{array}$} & 36,5 & 37,0 & 37,0 & 37,0 & 35,5 & 35,5 & 35,0 & 35,0 & 34,5 & 35,0 & 35,0 & 34,5 & 34,0 & 34,0 & 33,5 & 33,0 & 33,0 & 33,0 & 33,0 & 33,0 & 33,0 & 33,0 \\
\hline
\end{tabular}

Ort: Ortalama ve SD: Standart Sapma 
Çizelge 5. Tahir Çelik-Ankara caddeleri akşam (17:00-23:00) gürültü ölçümü verileri

\begin{tabular}{|c|c|c|c|c|c|c|c|c|c|c|c|c|c|c|c|c|c|c|c|c|c|c|c|}
\hline \multicolumn{2}{|c|}{$\begin{array}{l}\text { Ölçüm } \\
\text { Noktaları }\end{array}$} & 1 & 2 & 3 & 4 & 5 & 6 & 7 & 8 & 9 & 10 & 11 & 12 & 13 & 14 & 15 & 16 & 17 & 18 & 19 & 20 & 21 & 22 \\
\hline \multirow{4}{*}{$\begin{array}{l}\text { Ses } \\
\text { Seviyesi, } \\
\text { dBA }\end{array}$} & En az & 42,5 & 41,3 & 40,9 & \begin{tabular}{|l|}
43,1 \\
\end{tabular} & \begin{tabular}{|l|l|}
44,8 \\
\end{tabular} & \begin{tabular}{|l|}
48,6 \\
\end{tabular} & \begin{tabular}{|l|l|}
48,4 \\
\end{tabular} & 488,5 & 46,6 & 51,3 & 52,6 & \begin{tabular}{|l|}
51,2 \\
\end{tabular} & \begin{tabular}{|l|}
49,6 \\
\end{tabular} & \begin{tabular}{|l|l|}
54,4 \\
\end{tabular} & 51,0 & 51,4 & 50,4 & 51,9 & 42,5 & 40,9 & \begin{tabular}{|l|l|}
43,7 \\
\end{tabular} & \begin{tabular}{|l|l}
42,7 \\
\end{tabular} \\
\hline & \begin{tabular}{|l} 
En çok \\
\end{tabular} & 52,0 & 56,1 & 67,0 & \begin{tabular}{|l|l|}
74,2 \\
\end{tabular} & 71,2 & \begin{tabular}{|l|l|}
79,6 \\
\end{tabular} & 82,2 & \begin{tabular}{|l|}
81,3 \\
\end{tabular} & 75,2 & 81,0 & 76,7 & \begin{tabular}{|l|l|}
74,6 \\
\end{tabular} & 71,9 & 80,2 & 72,0 & \begin{tabular}{|l|}
75,7 \\
\end{tabular} & \begin{tabular}{|l|l|}
70,7 \\
\end{tabular} & 80,9 & 78,0 & \begin{tabular}{|l}
69,7 \\
\end{tabular} & \begin{tabular}{|l|}
56,9 \\
\end{tabular} & 73,9 \\
\hline & \begin{tabular}{|l|l} 
Ort \\
\end{tabular} & 45,9 & 48,3 & 51,6 & \begin{tabular}{|l|}
55,3 \\
\end{tabular} & 59,7 & \begin{tabular}{|l|}
61,7 \\
\end{tabular} & \begin{tabular}{|l|}
62,8 \\
\end{tabular} & \begin{tabular}{|l|}
63,0 \\
\end{tabular} & \begin{tabular}{|l|}
64,1 \\
\end{tabular} & \begin{tabular}{|l|}
64,8 \\
\end{tabular} & 64,6 & 62,3 & 62,8 & 66,1 & 62,9 & 64,0 & 60,4 & 64,6 & 60,8 & 55,4 & \begin{tabular}{|l|l}
49,9 \\
\end{tabular} & 55,6 \\
\hline & SD & 3,6 & \begin{tabular}{|l|l|}
5,7 \\
\end{tabular} & \begin{tabular}{|l|}
9,7 \\
\end{tabular} & \begin{tabular}{|l|}
12,2 \\
\end{tabular} & \begin{tabular}{|l|}
10,2 \\
\end{tabular} & 12,5 & \begin{tabular}{|l|}
12,2 \\
\end{tabular} & \begin{tabular}{|l|}
13,8 \\
\end{tabular} & 11,0 & 12,0 & 10,9 & 10,7 & \begin{tabular}{|l|l|}
9,1 \\
\end{tabular} & \begin{tabular}{|l|}
9,7 \\
\end{tabular} & 9,1 & 10,6 & \begin{tabular}{|l|}
9,7 \\
\end{tabular} & 11,7 & \begin{tabular}{|l|l|}
14,4 \\
\end{tabular} & 11,6 & \begin{tabular}{|l|l|}
4,8 \\
\end{tabular} & 12,7 \\
\hline \multicolumn{2}{|c|}{$\begin{array}{l}\text { Ortalama } \\
\text { rüzgâr hızı, } \mathrm{m} / \mathrm{s}\end{array}$} & 1,0 & 1,1 & 2,6 & 1,2 & 1,8 & 2,5 & 1,5 & 1,8 & 0,9 & 1,6 & 0,9 & 0,8 & 0,8 & 1,0 & 1,0 & 2,6 & 1,2 & 1,0 & 1,6 & 1,3 & 1,9 & 1,7 \\
\hline \multicolumn{2}{|c|}{$\begin{array}{l}\text { Ortalama } \\
\text { sicaklik, }{ }^{\circ} \mathrm{C}\end{array}$} & 20,0 & 20,3 & 20,5 & 20,8 & 21,1 & 21,9 & 22,1 & 22,4 & 22,3 & 22,3 & 22,2 & 22,2 & 22,1 & 22,1 & 22,1 & 22,1 & 22,1 & 22,0 & 22,0 & 21,8 & 21,7 & 21,7 \\
\hline \multicolumn{2}{|c|}{$\begin{array}{l}\text { Ortalama } \\
\text { nem, } \%\end{array}$} & 39,0 & 38,0 & 38,5 & 38,0 & 38,5 & 37,5 & 38,0 & 38,0 & 37,0 & 37,0 & 36,5 & 37,0 & 37,0 & 38,0 & 38,0 & 38,5 & 37,0 & 37,0 & 37,0 & 36,5 & 36,5 & 36,5 \\
\hline \multicolumn{2}{|c|}{$\begin{array}{l}\text { Ölçüm } \\
\text { Noktaları }\end{array}$} & 23 & 24 & 25 & 26 & 27 & 28 & 29 & 30 & 31 & 32 & 33 & 34 & 35 & 36 & 37 & 38 & 39 & 40 & 41 & 42 & 43 & 44 \\
\hline \multirow{4}{*}{$\begin{array}{l}\text { Ses } \\
\text { Seviyesi, } \\
\text { dBA }\end{array}$} & \begin{tabular}{|l|l} 
En \\
\end{tabular} & 41,1 & 39,0 & 42,5 & 47,5 & \begin{tabular}{|l|}
46,8 \\
\end{tabular} & \begin{tabular}{|l|}
51,1 \\
\end{tabular} & \begin{tabular}{|l|}
49,7 \\
\end{tabular} & \begin{tabular}{|l|}
51,9 \\
\end{tabular} & \begin{tabular}{|l|}
48,9 \\
\end{tabular} & \begin{tabular}{|l|}
52,0 \\
\end{tabular} & \begin{tabular}{|l|}
52,2 \\
\end{tabular} & \begin{tabular}{|l|}
52,8 \\
\end{tabular} & 53,1 & 53,1 & 49,6 & 53,1 & 54,2 & 51,2 & 41,6 & 41,3 & $\begin{array}{l}41,7 \\
\end{array}$ & 40,2 \\
\hline & En çok & 63,0 & 66,0 & 60, & \begin{tabular}{|l|}
65,8 \\
\end{tabular} & \begin{tabular}{|l|}
72,1 \\
\end{tabular} & 71,5 & 74,5 & \begin{tabular}{|l|l|}
78,8 \\
\end{tabular} & \begin{tabular}{|l|}
74,1 \\
\end{tabular} & \begin{tabular}{|l|}
73,3 \\
\end{tabular} & \begin{tabular}{|l|}
73,4 \\
\end{tabular} & \begin{tabular}{|l|}
71,7 \\
\end{tabular} & \begin{tabular}{|l|l|}
69,9 \\
\end{tabular} & \begin{tabular}{|l|l|}
79,2 \\
\end{tabular} & 75,4 & 74,8 & \begin{tabular}{|l|l|}
76,8 \\
\end{tabular} & 81,3 & 74,4 & 60,9 & \begin{tabular}{|l|l|}
57,1 \\
\end{tabular} & 52,1 \\
\hline & $\begin{array}{l}\text { Ort } \\
\end{array}$ & 49,1 & 49,4 & 51,6 & \begin{tabular}{|l|}
55,6 \\
\end{tabular} & \begin{tabular}{|l|}
57,1 \\
\end{tabular} & \begin{tabular}{|l|}
61,3 \\
\end{tabular} & \begin{tabular}{|l|l|}
62,4 \\
\end{tabular} & 63 & 61,6 & \begin{tabular}{|l|}
61,7 \\
\end{tabular} & \begin{tabular}{|l|l}
63,1 \\
\end{tabular} & \begin{tabular}{|l|}
62,7 \\
\end{tabular} & 61,4 & \begin{tabular}{|l|l|}
65,1 \\
\end{tabular} & \begin{tabular}{|l|l|}
62,3 \\
\end{tabular} & \begin{tabular}{|l|}
65,7 \\
\end{tabular} & 65,1 & 7,0 & 3,9 & 50,1 & \begin{tabular}{|l|}
47,9 \\
\end{tabular} & 45,2 \\
\hline & \begin{tabular}{|l|} 
SD \\
\end{tabular} & \begin{tabular}{|l|}
8,9 \\
\end{tabular} & 10,3 & \begin{tabular}{|l|}
7,2 \\
\end{tabular} & \begin{tabular}{|l|}
7,2 \\
\end{tabular} & \begin{tabular}{|c|}
9,7 \\
\end{tabular} & \begin{tabular}{|c|}
9,6 \\
\end{tabular} & \begin{tabular}{|l|}
10,1 \\
\end{tabular} & \begin{tabular}{|l|}
11,3 \\
\end{tabular} & \begin{tabular}{|l|}
11,8 \\
\end{tabular} & \begin{tabular}{|l|}
9,7 \\
\end{tabular} & \begin{tabular}{|l|}
8,8 \\
\end{tabular} & \begin{tabular}{|l|}
8,7 \\
\end{tabular} & \begin{tabular}{|l|}
8,3 \\
\end{tabular} & \begin{tabular}{|l|}
11,5 \\
\end{tabular} & \begin{tabular}{|l|}
10,3 \\
\end{tabular} & \begin{tabular}{|l|}
8,1 \\
\end{tabular} & 10,2 & \begin{tabular}{|l|}
12,3 \\
\end{tabular} & 12,4 & \begin{tabular}{|l|}
7,2 \\
\end{tabular} & \begin{tabular}{|l|l|}
5,6 \\
\end{tabular} & \begin{tabular}{|l|}
4,5 \\
\end{tabular} \\
\hline \multicolumn{2}{|c|}{$\begin{array}{l}\text { Ortalama } \\
\text { rüzgâr hızı, } \mathrm{m} / \mathrm{s}\end{array}$} & 1,3 & 2,5 & 1,5 & 1,3 & 1,9 & 1,6 & 2,1 & 1,9 & 1,4 & 1,2 & 1,6 & 1,4 & 1,9 & 1,5 & 1,4 & 2,6 & 1,5 & 1,6 & 2,0 & 2,2 & 1,7 & 1,7 \\
\hline \multicolumn{2}{|c|}{$\begin{array}{l}\text { Ortalama } \\
\text { sicaklik, }{ }^{\circ} \mathrm{C}\end{array}$} & 21,6 & 21,5 & 21,5 & 21,6 & 21,5 & 21,6 & 21,5 & 21,7 & 21,6 & 21,6 & 21,8 & 21,9 & 22,0 & 22,0 & 22,1 & 22,4 & 22,4 & 22,4 & 22,2 & 22,2 & 22,2 & 22,2 \\
\hline \multicolumn{2}{|c|}{$\begin{array}{l}\text { Ortalama } \\
\text { nem, } \%\end{array}$} & 36,5 & 36,5 & 36,5 & 36,5 & 35,5 & 35,0 & 35,5 & 36,5 & 36,5 & 37,0 & 36,5 & 37,0 & 36,0 & 36,0 & 36,0 & 36,5 & 36,5 & 36,0 & 36,0 & 36,5 & 36,5 & 36,5 \\
\hline
\end{tabular}

Ort: Ortalama ve SD: Standart Sapma

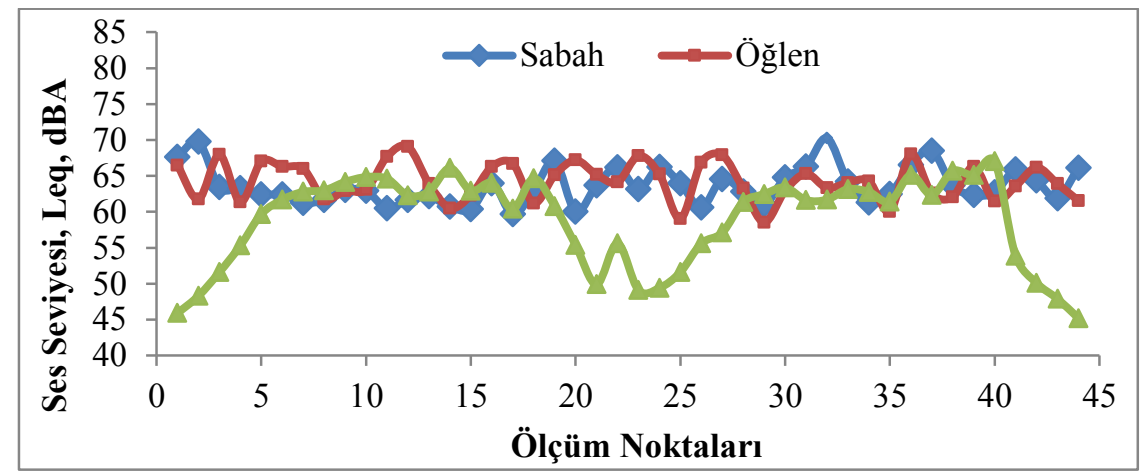

Şekil 3. Sabah, öğlen ve akşam ortalama gürültü seviye düzeylerine ilişkin kıyaslama

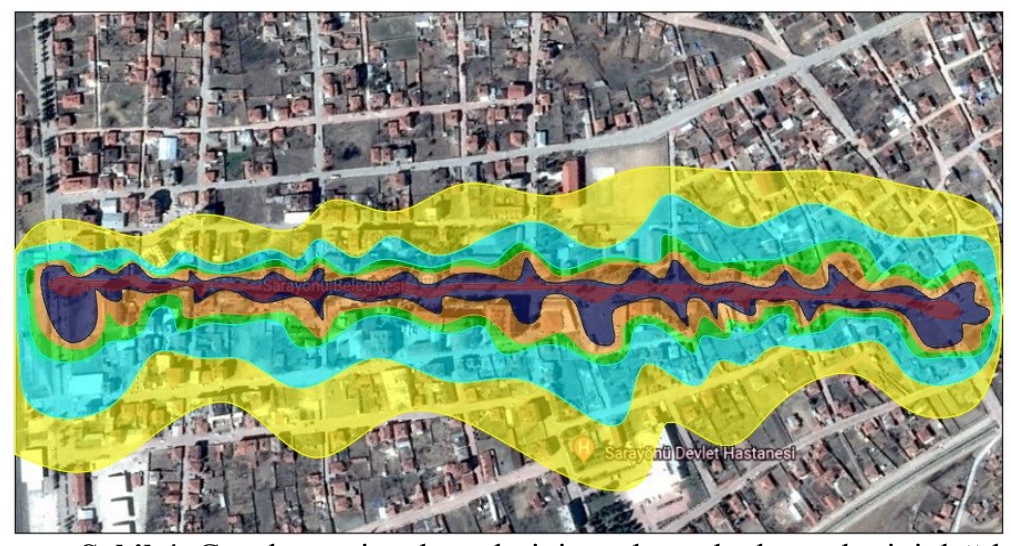

$>90$ dBA

90-80 dBA

80-70 dBA

70-60 dBA

60-50 dBA

$50-30 \mathrm{dBA}$

Şekil 4. Gürültü seviye düzeylerinin serbest alanlara tahmini dağılım gösterimi 
04/06/2010 tarih ve 27601 sayılı Resmi Gazete'de yayımlanarak yürürlüğe giren Çevresel Gürültünün Değerlendirilmesi ve Yönetimi Yönetmeliği'nin Ek 7'de yer alan Kara Yolu Çevresel Gürültü Sınır Değerleri Çizelge 6'da verilmiştir. Çizelge 6'da verilen sınır değerler ile ilçe merkezinde yapılan ölçüm ortalama değerleri arasında büyük farklar bulunmamaktadır. $\mathrm{Bu}$ bakımdan ilçede ölçülen gürültü düzeyleri ortalamaları yönetmeliğin sınır değerlerinin birkaç puan üzerinde olduğu tespit edilmiştir. Çizelge 7'de literatürde daha önce yapılmış gürültü çalışmaları ile bu çalışma kıyaslanmasını sağlamak amacıyla makaleye eklenmiştir. Sonuçların literatürde yer alan diğer yapılan çalışmaların sonuçlarına yakın ve uyum sağlamakta olduğu görülmüştür.

Çizelge 6. Kara yolu çevresel gürültü sınır değerleri [24]

\begin{tabular}{|c|c|c|c|c|c|c|}
\hline \multirow{2}{*}{ Alanlar } & \multicolumn{3}{|c|}{$\begin{array}{l}\text { Planlanan/Yenilenmiş/Onarılmış } \\
\text { yollar } \\
\end{array}$} & \multicolumn{3}{|c|}{ Mevcut yollar } \\
\hline & $\begin{array}{c}\text { Lgündüz } \\
\text { (dBA) }\end{array}$ & $\begin{array}{l}\text { Lakşam } \\
\text { (dBA) }\end{array}$ & $\begin{array}{c}\text { Lgece } \\
(\text { dBA })\end{array}$ & $\begin{array}{l}\text { Lgündüz } \\
\text { (dBA) }\end{array}$ & $\begin{array}{l}\text { Lakşam } \\
\text { (dBA) }\end{array}$ & $\begin{array}{c}\text { Lgece } \\
(\text { dBA) }\end{array}$ \\
\hline $\begin{array}{l}\text { Gürültüye hassas kullanımlardan eğitim, kültür } \\
\text { ve sağlık alanları ile yazlık ve kamp yerlerinin } \\
\text { ağırlıklı olduğu alanlar }\end{array}$ & 60 & 55 & 50 & 65 & 60 & 55 \\
\hline $\begin{array}{l}\text { Ticari yapılar ile gürülttüye hassas kullanımların } \\
\text { birlikte bulunduğu alanlardan konutların yoğun } \\
\text { olarak bulunduğu alanlar }\end{array}$ & 63 & 58 & 53 & 68 & 63 & 58 \\
\hline $\begin{array}{l}\text { Ticari yapılar ile gürülttüye hassas kullanımların } \\
\text { birlikte bulunduğu alanlardan işyerlerinin yoğun } \\
\text { olarak bulunduğu alanlar }\end{array}$ & 65 & 60 & 55 & 70 & 65 & 60 \\
\hline Endüstriyel alanlar & 67 & 62 & 57 & 72 & 67 & 62 \\
\hline
\end{tabular}

Çizelge 7. Literatürde yer alan daha önce yapılmış diğer çalışmalar ile karşılaştırma

\begin{tabular}{|l|c|c|c|c|c|}
\hline Araştırma Bölgesi & Ölçüm Zamanı & $\begin{array}{c}\text { Ölçüm } \\
\text { Noktası }\end{array}$ & Ölçüm Cihazı & $\begin{array}{c}\text { Gürültü } \\
\text { Değerleri, } \\
\text { Leq, dB(A) }\end{array}$ & Referans \\
\hline Merkez/Giresun & Sabah, öğle ve akşam & 99 & Testo 815 & $69-76$ & {$[4]$} \\
\hline Merkez/Çanakkale & Sabah ve akşam & 16 & SL-824 & $63-76$ & {$[5]$} \\
\hline Merkez/Sakarya & Sabah, akşam ve gece & 38 & Extech HD600 & $>65$ & {$[6]$} \\
\hline Merkez/Trabzon & Sabah ve akşam & 18 & SVAN957 & $>60$ & {$[14]$} \\
\hline Merkez/Sivas & Sabah, öğle ve akşam & 20 & TES 1350 & $>65$ & {$[22]$} \\
\hline Zagreb/Hurvatistan & Sabah ve öğle & 2 & $\begin{array}{c}\text { Brüel \& Kjær } \\
2260\end{array}$ & $55,1-66,8$ & {$[25]$} \\
\hline Yakutiye/Erzurum & Sabah, öğle ve akşam & 8 & CEL 254 K2 & 60,07 & {$[26]$} \\
\hline Curitiba/Brezilya & Sabah, öğle ve akşam & 232 & $\begin{array}{c}\text { B\&K 2238 ve } \\
\text { B\&K 2250 }\end{array}$ & $>65$ & {$[27]$} \\
\hline $\begin{array}{l}\text { Cumhuriyet } \\
\text { Üniversitesi/Sivas }\end{array}$ & Sabah, öğle ve akşam & 9 & TES 1350 & $65-80$ & {$[28]$} \\
\hline $\begin{array}{l}\text { Avşar Kampüsü/ } \\
\text { Kahramanmaraş }\end{array}$ & Sabah, öğle ve akşam & 36 & $\begin{array}{c}\text { Delta OHM } \\
\text { HD2010 }\end{array}$ & $39-71$ & {$[29]$} \\
\hline $\begin{array}{l}\text { Kirmanşah Üniversitesi } \\
\text { KUMS), İran }\end{array}$ & Öğle & 30 & 5969 Casella-BS & $30-59$ & {$[30]$} \\
\hline Tekstil Fabrikası, Kayseri & Öğle & 4 & SVAN957 & $73,4-94,4$ & {$[31]$} \\
\hline Selanik/Yunanistan & Sabah, öğle ve akşam & 5 & $\begin{array}{c}\text { Electronic noise } \\
\text { device }\end{array}$ & $70-82$ & {$[32]$} \\
\hline Sarayönü/Konya & Sabah, öğle ve akşam & 44 & CEM DT-852 & $50-70$ & $\begin{array}{c}B u \\
\text { çalışma }\end{array}$ \\
\hline
\end{tabular}


Araştırma kapsamında elde edilen veriler 1 şı̆̆ında bazı çevresel gürültü azaltım önerileri sunacak olursak;

- Bitişik nizamda yapılan konut ve iş yerleri caddelerin de dar olmasından dolayı gürültü yankılayıcı ve yansışım özelliği göstermekte olup caddeye hapsolmakta, buna izin verilmemeli,

- İlçe merkezinde yapılacak peyzaj ve ağaçlandırma çalışmaları sayesinde yeşil bitki örtüsü (doğal bariyer görevi üstleneceğinden) artırılmalı,

- İlçe merkezinde yeterli otopark bulunmamasından dolayı oldukça fazla araç trafiği oluşmaktadir. Araçlar otopark bulma çabası veya park edenlerin gelişigüzel park etmesi sebebiyle gürültünün artmasına sebep olmaktadır. Araçlar için yeterli bir otopark yapılması sağlanmalı,

- İlçe merkezinde yer alan otogar yerinin merkez dışında daha uygun ve modern bir yer tahsis edilmek suretiyle araç trafiğine katkısı azaltılmalı,

- İlçe içerisinde bulunan yollarda varsa çukur ve alçaklıklar düzeltilmeli ve araçların ani fren yaparak ses kaynağı olmalarının önüne geçilmeli,

- İlçe içerisindeki tüm araçların fenni muayeneleri yaptırılmalı ve gerekirse susturucu vb. malzemeler kullanılması sağlanmalı,

- İlçe merkezindeki motor, motosiklet vb. araçların yüksek ses çıkarmaları engellenmeli,

- Tüm şoförler gereksiz klakson kullanımı konusunda uyarılmalı ve sürekliliği sağlanmalı,

- Toplumun gürültü konusunda bilinçlenmesi için eğitimler düzenlenmeli ve Çevre ve Şehircilik Bakanlığı Alo 181 nolu telefon hatt tanitılmalıdir.

\section{SONUÇLAR}

Araştırma kapsamında Konya İli, Sarayönü İlçe merkezinde insan faaliyetlerinin en yoğun olduğu alan hattında yürütülmüştür. Bu çalışma ile ulaşım, inşaat, yerleşim ve ticaret gibi ilçe sakinlerinin yoğun olarak kullandığı Ankara ve Tahir Çelik caddelerinde sabah 08:00-23:00 saatleri arasinda
Mart, Nisan ve Mayıs aylarında ölçümler gerçekleştirilmiştir. Gündüz ölçümlerinde 45,5 ile 102,5 dBA aralığından ses seviyeleri seyretmiştir. Öğlen ölçümlerinde ise 44,3 ile $89,8 \mathrm{dBA}$ aralığında ölçülmüştür. Gerçekleştirilen akşam ölçümlerinde ise 39,0 ile 82,2 dBA aralığında olduğu bulunmuştur. Tüm periyotların ölçüm ortalamalarına bakıldığında ise 50-70 dBA aralığında olduğu görülmüştür. Şekil 3 . incelendiğinde ortalama gürültü seviyeleri sabah 63,6 dBA, öğlen 64,2 dBA ve akşam için ise $58,8 \mathrm{dBA}$ olduğu hesaplanmıştır. İlçemiz anlık gürültü piklerini azaltılması ile çok gürültü olmayan bir kategoride yer aldığını söyleyebiliriz. Genel olarak ölçüm yapılan caddelerin ortalama ses düzey değerlerine bakıldığında çevresel gürültü sınır değerleri ile çok küçük farklar olduğu tespit edilmiştir.

\section{TEŞEKKÜR}

$\mathrm{Bu}$ araştırma Selçuk Üniversitesi, Bilimsel Araştırmalar Koordinatörlüğü tarafından kabul edilen 18402017 numaralı proje ile desteklenmiştir.

\section{KAYNAKLAR}

1. Akça, A., 2009. Afyonkarahisar Şehir Merkezi Gürültü Haritasının Oluşturulması ve Gürültünün İnsan Sağlığı Üzerindeki Etkisi, Yüksek Lisans Tezi,. Afyon Kocatepe Üniversitesi, Fen Bilimleri Enstitüsü, Afyonkarahisar.

2. Bayraktar, Ş., 2006. İzmit Kent Merkezinin Gürültü Kirliliği, Yüksek Lisans Tezi, . Kocaeli Üniversitesi, Fen Bilimleri Enstitüsü, Kocaeli.

3. Avşar, Y., Arslankaya, E., Gönüllü, M.T., 1999. Barbaros Bulvarı Gürültü Düzeyi Tesbit Çalışması,. Türkiye'de Çevre Kirlenmesi Öncelikleri Sempozyumu III, Gebze Yüksek Teknoloji Enstitüsü, 1009-1015.

4. Kalıpc1, E., 2007. Giresun İl Merkezinde Gürültü Kirliliği Ölçümü ve Haritasının Hazırlanması, Yüksek Lisans Tezi,. Selçuk Üniversitesi, Fen Bilimleri Enstitüsü, Çevre Mühendisliği Anabilim Dalı, Konya. 
5. Ilgar, R., 2012. Çanakkale Şehir İçi Trafiğindeki Araç Kaynaklı Gürültü Kirliliğine Yönelik Ön Çalışma,. Zeitschrift für die Welt der Türken ZfWT 4(1).

6. Morgül, K., Dal, H., 2012. Sakarya İli Şehir Merkezinin Gürültü Kirliliği Üzerine Bir Ön Çalışma,. SAÜ Fen Bilimleri Dergisi, 16(2), 83-91.

7. ÇOB, 2011. Çevre ve Orman Bakanlığ Yönetimi Genel Müdürlüğü, Çevresel Gürültü Ölçüm ve Değerlendirme Kılavuzu, Ankara, 1-106.

8. Akdağ, N., 2002. Kent Planlamada Gürültü Haritalarının Önemi: Barbaros Bulvarı Çevresi Örneği,. 6. Ulusal Akustik Kongresi, Antalya.

9. Kalıpçı, E., 2017. Avanos İlçe Merkezinde Trafik Kaynaklı Gürültü Kirliliğinin Mekansal Analizi. Nevşehir Bilim ve Teknoloji Dergisi, 6(1), 20-29.

10. Tüik, http://www.tuik.gov.tr/ilgostergeleri/iller/ konya.pdf, (Erişim Tarihi: 27.02.2018). 2013.

11. Alpözen, C.M., 2017. Konya-Sarayönü Gözlü Tarım İşletmesi Müdürlüğüne ait Sulu Ziraat Alanlarındaki Su Kaynaklarının Sulama Suyu Kalitesi Yönünden Değerlendirilmesi, Yüksek Lisans Tezi, Selçuk Üniversitesi, Tarımsal Yapılar ve Sulama Anabilim Dalı, Konya.

12. Sarayönü, http://www.sarayonu.gov.tr/yolHaritasi, Sarayönü Kaymakamlığı Web Adresi, 27.02.2018, Konya. 2018.

13. Toklu, S., 2011. Motorlu Araçlardan Kaynaklanan Gürültü Kirliliği: Bir Bölge Çalışması, Trafik Planlaması ve Uygulaması, Yüksek Lisans Tezi, Gazi Üniversitesi, Fen Bilimleri Enstitüsü, Ankara.

14. Bayramoğlu, E.B. Işık, Ö., Demirel, Ö., 2014. Gürültü Kirliliğinin Kent Parklarına Etkisi ve Çözüm Önerileri: Trabzon Kenti Örneği. İnönü Üniversitesi Sanat ve Tasarım Fakültesi, 4(9), 35-42.

15. Parbat, D.K., Nagarnaik B.P., 2007. Assessment and ANN Modelling of Noise Levels at Major Road Intersections in an Indian Intermediate City. Journal of Research in Science, Computing and Engineering, 4(3), 39-49.

16. Patrick, F.C., 1977. Environmental Noise Pollution. J. Wiley and Sons Inc, New York.
17. Karpuzcu, M., 1996. Çevre Kirlenmesi ve Kontrolü. Kubbealtı Neşriyat, Özel Matbaası: Kubbealtı Dizgi Merkezi, 5.

18. Demirkale Y.S., 2007. Çevre ve Yapı Akustiği, Mimarlar ve Mühendisler için El Kitabı. İstanbul: Birsen Yayınevi.

19. Koushki, P.A., 1999. Trafficnoise in Kuwait: Profilesand Model in Gresidents' Perceptions,. Journal of Urban Planning and Development, 101-109.

20. Baaj, M.H., El-Fadel, M., Shazbak, S.M., Saliby, E., 2001. Modeling Noise at Elevated Highways in Urban Areas: a Practical Application. Journal of Urban Planning and Development, 169.

21. Leong, S.T., Lartanakul, P., 2003. Monitor in Gandas Sess Ment of Daily Exposure of Road Side Worker Stotraffic Nois Elevels in an Asiancity: a Casestudy of Bangkok Streets. Environemental Monitoringand Assessment, 85, 69-85.

22. Özyonar, F., Peker, İ., 2008. Sivas Kent Merkezindeki Çevresel Gürültü Kirliliğinin Araştırılması. Ekoloji 18(69), 75-80.

23. Dursun, Ş., Özdemir, C., 1999. Konya İl Merkezinde Gürültü Kirliliği Haritasının Hazırlanması, Konya,. Proje No: 97-081, 4-24.

24. CGDYY, 2010. Çevresel Gürültünün Değerlendirilmesi ve Yönetimi Yönetmeliği. Resmi Gazete, 27601(ER:19/12/2018).

25. Džambas, T.S., Lakušić, Dragčević, V., 2018. Traffic Noise Analysis in Railway Station Zones. Applied Acoustics, 137, 27-32.

26. Özer, S., 2015. Kent Merkezlerindeki Parklarda Gürültü Düzeyi: Yakutiye Park1 Örneğinde. Iğdır Üni. Fen Bilimleri Enst. Der., 5(3), 43-48.

27. Fiedler, P.E.K., Zannin, P.H.T., 2015. Evaluation of Noise Pollution in Urban Traffic Hubs-Noise Maps and Measurements. Environmental Impact Assessment Review, 51, 1-9.

28. Özyonar, F., Ömür, G., Hamdi, H., Önder, G., 2018. Assesment of on-Campus Noise Levels at Cumhuriyet University. Fresenius Environmental Bulletin. 27p.

29. Doygun, N., 2016. Kahramanmaraş Sütçü İmam Üniversitesi Avşar Yerleşkesinde Trafik 
Gürültüsünün İncelenmesi. İnönü Üniversitesi Sanat ve Tasarım Dergisi, 6(14), 1-11.

30. Nafez, A., Lotfi, S., Raziyeh, R., Reza, S., (2017). Assessment the Noise Level in Libraries and Dormitories of Kermanshah University of Medical Sciences in 2016 (Kermanshah, Iran). 26(7), 4890-4893.

31. Soylu, M., Gökkuş, Ö., 2016. Endüstriyel Kaynaklı Gürültü Kirliliğinin Araştırılması ve Bir Tekstil Farbrikasında Uygulma Örneği, Erciyes Üniversitesi, Fen Bilimleri Enstitüsü Dergisi, 32(2), 1-7.

32. Tsakalidis, A., Kehagia, F., PitsiavaLatinopoulou, M., 2017. Examining the Correlation of Noise Levels with Traffic Characteristics in an Urban Area: The Case of Thessaloniki. 26(9), 5616-5621. 
